\title{
A cohort study comparing internal fixation for undisplaced versus hip arthroplasty for displaced femoral neck fracture in the elderly: a pilot study for a clinical trial
}

Sebastian Mukka ${ }^{1}$, Pontus Sjöholm¹, Athir Aziz ${ }^{1}$, Thomas Eisler ${ }^{2}$ Bakir Kadum ${ }^{3 *}$, Ferid Krupic ${ }^{4}$, Per Morberg ${ }^{1}$ and Arkan Sayed-Noor ${ }^{1}$

\begin{abstract}
Introduction: The literature regarding undisplaced femoral neck fractures (FNF) is sparse. The aim of this prospective feasibility study is to compare the clinical outcome after undisplaced FNF treated with internal fixation (IF) and displaced FNF treated with hip arthroplasty. We hypothesized that hip arthroplasty would give a lower incidence of reoperations.
\end{abstract}

Methods: A total of 235 patients were included with a median age of 84 years (range 65-99). A consecutive series of 65 patients with undisplaced FNF were treated with IF, and 170 patients with displaced FNF were treated with either a total hip arthroplasty or a hemiarthroplasty. Follow-up interviews were conducted at 1 year using the Harris Hip Score (HHS), WOMAC, and pain numeric rating scale (PNRS). The minimum follow-up time was 22 months. There was no difference in baseline data between the groups.

Results: Nineteen (8\%) hips required reoperation at least once at a mean of 6 months (range 0-35). The rate of reoperation was higher in the IF group compared to the hip arthroplasty group (13.8\% vs. 5.9\%, 95\% Cl 0.9-6.4). The overall 1-year and 2-year mortality was $28 \%$ and $40 \%$, respectively, with no difference between the groups. The most common reasons for reoperations in the IF group were non-union and avascular necrosis, and 6 patients were treated with hip or excision arthroplasty. In the arthroplasty group, the most common indications were deep infection and dislocation. We did not find any differences between the groups in terms of HHS, WOMAC, and PNRS.

Conclusions: In this feasibility study, we found no differences in patient-reported outcomes between the groups although IF required a higher rate of reoperations. Further randomized trials are needed to establish the optimal treatment of undisplaced FNF in the elderly.

Trial registration: ClinicalTrial.org, NCT03392285. Retrospectively registered on 5 February 2018.

Keywords: Hip fractures, Undisplaced, Displaced, Internal fixation, Arthroplasty, Reoperation

* Correspondence: bakir.kadum17@gmail.com

${ }^{3}$ Department of Biomedical and Clinical Sciences (BKV), Linköping University, Linköping, Sweden

Full list of author information is available at the end of the article

(c) The Author(s). 2020 Open Access This article is licensed under a Creative Commons Attribution 4.0 International License, which permits use, sharing, adaptation, distribution and reproduction in any medium or format, as long as you give appropriate credit to the original author(s) and the source, provide a link to the Creative Commons licence, and indicate if changes were made. The images or other third party material in this article are included in the article's Creative Commons licence, unless indicated otherwise in a credit line to the material. If material is not included in the article's Creative Commons licence and your intended use is not permitted by statutory regulation or exceeds the permitted use, you will need to obtain permission directly from the copyright holder. To view a copy of this licence, visit http://creativecommons.org/licenses/by/4.0/ The Creative Commons Public Domain Dedication waiver (http://creativecommons.org/publicdomain/zero/1.0/) applies to the data made available in this article, unless otherwise stated in a credit line to the data. 


\section{Introduction}

The incidence and healthcare burden of femoral neck fractures (FNFs) are forecasted to increase in the future due to an aging population [1]. FNFs are classified as undisplaced or displaced. Doubts have been raised regarding the results of the internal fixation of minimally displaced FNF [2]. In elderly patients, reoperation rates ranging from 8 to $19 \%$ have been reported [2-5]. The alternative treatment using hip arthroplasty is controversial. However, modern hip arthroplasty provides a hip that provides immediate unrestricted mobilization and may lower rates of reoperation, despite the increased risk for postoperative infection [6].

There is a need for large national or international, multicenter randomized clinical trials to improve the care of hip fracture patients [7-9]. Displaced femoral neck fracture in the elderly is mainly treated with hip arthroplasty in contrast to minimally displaced or undisplaced fracture which is mainly treated with internal fixation. This allows for a comparative study in order to extrapolate the results of a displaced femoral neck fracture population treated with arthroplasty to the possible results of arthroplasty for minimally displaced or undisplaced fracture.

\section{Rationale for a pilot study}

The aim of the present prospective pilot study is to compare the clinical outcome after undisplaced and minimally displaced FNF treated with internal fixation (IF) and displaced FNF treated with hip arthroplasty, in order to provide baseline data for a sample size calculations for a large national registry-based randomized controlled study [10].

\section{Specific pilot objectives}

The objectives are to evaluate the risk for reoperation, patient-reported outcome, and mortality after treatment of FNF with either hip arthroplasty or IF and to be able to perform a sample size calculation for a randomized controlled trial.

\section{Patients and methods}

\section{Study setting}

The study was conducted between February 2012 and October 2015 at the Department of Orthopaedics, Sundsvall Hospital, Sweden, which is an emergency hospital, affiliated to Umeå University, and provides medical care to a catchment area of approximately 160,000.

\section{Patients}

We included a consecutive series of all patients aged 65 years and above who were treated for a minimally displaced or undisplaced (Garden I or II) FNF with IF or for a displaced FNF with a primary hip arthroplasty by a direct lateral approach. Either a consultant orthopedic surgeon or a registrar performed all operations on the day of admission or the following day. The routine at our department is to perform IF for minimally displaced or undisplaced fracture (Garden I-II) FNF and hip arthroplasty for displaced (Garden III-IV) FNF in patients aged above 65 years. Total hip arthroplasty (THA) is used in the relatively young (up to 79 years) and active patients, in those with rheumatoid or osteoarthritic changes in the affected hip. Hemiarthroplasty (HA) is used in older (> 79) less active patients, those with low demands, those with short expected lifespan, and those with cognitive dysfunction. The final decision of whether to choose a THA or HA was made according to the surgeon's preference and the patient's level of activity. We included all eligible patients with a displaced FNF treated with a hip arthroplasty using a direct lateral approach.

IF was performed with the patient on a fracture table and the fracture visualized with an image intensifier and was fixed with two cannulated screws (Olmed; DePuy/ Johnson \& Johnson, Sollentuna, Sweden). In the anteroposterior projection, the distal screw was aimed at the level of the lesser trochanter to rest on the medial inferior cortex of the femoral neck. The proximal screw was positioned parallel to and at least $1 \mathrm{~cm}$ from the distal screw. Low-molecular-weight heparin was administered for 10-30 days postoperatively. Antibiotic prophylaxis was given on the day of surgery.

A cemented HA or THA was used through a direct lateral approach in the lateral decubitus position according to Hardinge. The HA was performed using the cemented SP II Lubinus system with a modular unipolar (Link ${ }^{\bullet}$ unipolar head, Warsaw, Germany) or bipolar head (Vario cup, Link ${ }^{\bullet}$ Warsaw, Germany). The acetabular components were either a cemented acetabular cup (Link $^{\bullet}$ Lubinus $^{\bullet}$ Hip Acetabular Cup, Warsaw, Germany) or a cemented dual-mobility cup (Avantage ${ }^{\circ}$, Biomet, Valence, France) based on the preference of the treating surgeon. All patients with a displaced FNF treated with a hip arthroplasty through a direct lateral approach during the inclusion period were included. Antibiotic-loaded bone cement was used for all patients (Optipac, Biomet, Sweden). Prophylactic antibiotics were administered 30 min preoperatively and 2 more times over 24 h postoperatively. Low-molecular-weight heparin was administered for 10-30 days postoperatively. All patients were mobilized during the first postoperative day with full weight-bearing according to a standard physiotherapeutic program without any restrictions.

\section{Data collection and follow-up}

Using the unique Swedish personal identification number, we collected data by a combination of a search of 
the in-hospital medical database and follow-up visits. All patients were followed up until 2017 or until death. The minimum follow-up time was 22 months. We collected patient data including age, sex, ASA score, cognitive status, type of surgical treatment, and length of operation. The reoperation rate and mortality during the study period were also documented. An independent research nurse performed follow-up interviews 1 year postoperatively using the following patient-reported outcome measurements: Harris Hip Score (HHS), Western Ontario and McMaster Universities Arthritis (WOMAC) questionnaires, and pain numeric rating scale (PNRS) [11-14]. Data will be available on request from the corresponding author.

\section{Statistics}

Student's $t$ tests and chi-square tests were used for continuous normal and ordinal data, respectively. All tests were 2-sided. For the PROM variables HHS, WOMAC, and PNRS, we used a generalized linear regression model to detect the differences between the 2 groups. Logistic regression was performed in order to evaluate the factors associated with reoperations. The study design and patients' follow-up ensure non-informative censoring. The mortality during the study period was high and might therefore have affected the results obtained and decrease the initial power. A multivariable model adjusted for surgical treatment, age, sex, cognitive status, and ASA category (1-2 or 3-4) was included in the analysis. The generalized linear model was used because neither WOMAC nor HHS was normally distributed. Gamma distribution was used due to the right skewness of the curves. The associations are presented as odds ratios (OR) with 95\% confidence intervals (CI). In each of the analyses made, there were 5 covariates. If $10-20$ patients were required for each covariate included in the analysis, then the number of patients would be sufficient. Kaplan-Meier survival analysis was used to compare 1and 2-year mortality between the groups. Statistical analysis was performed using SPSS $^{\circ}$ (IBM SPSS Statistics for Macintosh, Version 22.0, IBM Corp, Armonk, NY, USA). Trial registration: ClinicalTrials.gov (identifier: NCT03392285).

\section{Results}

\section{Study subjects and descriptive data}

A total of 235 patients were included in the study with a median age of 83 years (range 65-99) (Table 1). Seven patients sustained bilateral FNF, and only the first fracture was included in the analysis. Sixty-five patients with undisplaced FNF were treated with IF, and 170 patients with displaced FNF were treated with hip arthroplasty (152 received HA and 18 THA). Figure 1 shows the flow of patients through the study. The baseline characteristics of
Table 1 Study population characteristics. Continuous variables are presented as mean and range

\begin{tabular}{lll}
\hline & $\begin{array}{l}\text { Internal fixation } \\
n=65\end{array}$ & $\begin{array}{l}\text { Hip arthroplasty } \\
n=170\end{array}$ \\
\hline Age & $83(61-98)$ & $83(64-99)$ \\
Sex & & \\
Male & $21(32 \%)$ & $54(32 \%)$ \\
Female & $44(68 \%)$ & $116(68 \%)$ \\
Side & & \\
Right & $27(42 \%)$ & $77(45 \%)$ \\
Left & $38(58 \%)$ & $93(55 \%)$ \\
Cognitive status & & $100(59 \%)$ \\
Lucid & $36(55 \%)$ & $62(36 \%)$ \\
Impairment & $29(45 \%)$ & $8(5 \%)$ \\
Missing & $0(0 \%)$ & $152(89 \%)$ \\
Surgical treatment & & $18(11 \%)$ \\
Hemiarthroplasty & $0(0 \%)$ & $0(0 \%)$ \\
Total hip arthroplasty & $0(0 \%)$ & $94(55 \%)$ \\
Internal fixation & $65(100 \%)$ & $3(2 \%)$ \\
ASA & & \\
$1-2$ & $33(51 \%)$ & $29(45 \%)$ \\
$3-4$ & $3(4 \%)$ & \\
Missing & & \\
\hline
\end{tabular}

the study groups are presented in Table 1 and showed no statistical differences between them. The median followup time was 26 months (range 0-56 months). The minimum follow-up time was 22 months. The mean length of operation was $35 \mathrm{~min}$ in the IF group and $90 \mathrm{~min}$ in the hip arthroplasty group.

\section{Reoperation}

Nineteen (8.0\%) hips required reoperation at least once at a mean of 6 months (range 0-35) postoperatively (Table 2). All reoperations were performed during the first 20 months except for 1 periprosthetic femoral fracture that occurred 35 months postoperatively. The rate of reoperation was higher in the IF group compared to the arthroplasty group (13.4\% vs. $5.9 \%, 0.9-6.4)$ (Table 3$)$. The most common reasons for reoperations in the IF group were non-union/avascular necrosis where 6 patients were reoperated with hip arthroplasty (THA $n=2$, HA $n=3$ ) or an excision arthroplasty $(n=1)$. Three patients were reoperated with the removal of screws. In the arthroplasty group, the most common indication for reoperation was deep infection (3.5\%) (Table 2). Patients with deep infection were treated with debridement, antibiotics, irrigation, and implant retention without any further reoperations. Six patients $(3.6 \%)$ in the arthroplasty group had dislocation in whom 4 patients (2.4\%) treated with closed reduction and 2 patients $(1.2 \%)$ needed open surgical reduction. 


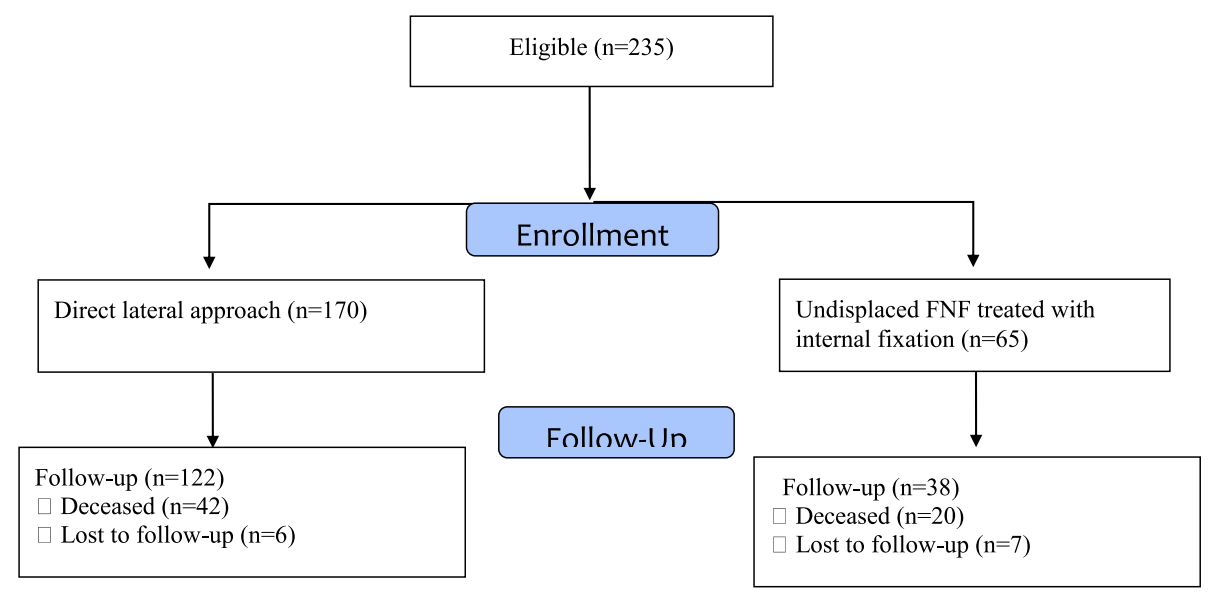

Fig. 1 Flowchart

\section{Patient-reported outcome}

We did not find any differences between the two groups in terms of HHS (IF 67 vs. arthroplasty 70), WOMAC (79 vs. 80 ), and PNRS (2.7 vs. 2.1 ) (Table 3 ), also when adjusting for confounders: age, sex, ASA category (1-2, 3-4), and cognitive status (Table 4). There was a tendency towards a higher level of pain (PNRS) in the IF group (2.7 vs. 2.0).

\section{Mortality}

The overall 1-year mortality was 28\% (65 of 235 patients). The overall 2-year mortality was $40 \%$ (95 of 235 patients). Neither 1-year mortality (IF $31 \%$ vs. arthroplasty $27 \%$ ) nor 2 -year mortality (IF $45 \%$ vs. arthroplasty $39 \%$ ) differed between the groups.

\section{Discussion}

In this feasibility study, we did not find any significant differences in patient-reported outcome measures between the two groups although there was a tendency that patients with undisplaced or minimally displaced FNF treated with IF had more pain and a higher rate of reoperations.

Table 2 Reoperations presented as number of patients and percentage

\begin{tabular}{lll}
\hline & $\begin{array}{l}\text { Internal fixation } \\
n=65\end{array}$ & $\begin{array}{l}\text { Hip arthroplasty } \\
(n=170)\end{array}$ \\
\hline Mechanical failure/non-union/AVN & $6(9.2 \%)$ & $0(0 \%)$ \\
Extraction of osteosynthesis & $3(4.6 \%)$ & $0(0 \%)$ \\
Deep infection & $0(0 \%)$ & $6(3.5 \%)$ \\
Revision due to dislocation & $0(0 \%)$ & $2(1.1 \%)$ \\
Acetabular erosion & $0(0 \%)$ & $1(0.6 \%)$ \\
Periprosthetic fracture & $0(0 \%)$ & $1(0.6 \%)$ \\
\hline
\end{tabular}

Recent studies indicate that by using either a modern modular THA or HA, performed by a direct lateral approach, the risk for revision due to dislocation may be reduced to 2\% [15]. The risk of periprosthetic femoral fractures is reduced to below $1 \%$ by the use of cemented composite-beam femoral implants [16, 17]. Periprosthetic joint infection poses a major challenge but might be reduced with the use of high-dose dual-impregnated antibiotic-laden cement to approximately $1-2 \%$ [18]. These improvements raise the question of whether arthroplasty might improve the outcome of undisplaced or minimally displaced FNF in the elderly [2]. There are limited data comparing IF and hip arthroplasty for these fractures, and trials have been called for to optimize the surgical treatment [2].

Table 3 Logistic regression presenting adjusted odds ratio (OR) for reoperations with 95\% confidence interval (95\% Cl)

\begin{tabular}{lll}
\hline Variable & Reoperation & \\
\cline { 3 - 3 } & OR & $95 \% \mathrm{Cl}$ \\
\hline Cognitive impairment & 1.0 & - \\
No & 1.1 & $0.4-3.0$ \\
Yes & & \\
Surgical treatment & 1.0 & - \\
$\quad$ Hip arthroplasty & 2.3 & $0.9-6.4$ \\
Internal fixation & 1.0 & $0.9-1.1$ \\
Age & & \\
Sex & 1.0 & - \\
Male & 0.9 & $0.3-2.6$ \\
Female & & - \\
ASA & 1.0 & $0.7-6.2$ \\
1-2 & 2.1 & \\
3-4 & &
\end{tabular}


Table 4 Patient-reported outcome variables. Generalized linear model regression including adjusted variables for Harris Hip Score (HHS) and WOMAC with 95\% confidence interval (95\% Cl). Estimated marginal means (EM) for each covariate are included

\begin{tabular}{|c|c|c|c|c|c|c|}
\hline \multirow[t]{2}{*}{ Variable } & \multirow[t]{2}{*}{ EM } & \multicolumn{2}{|c|}{ WOMAC } & \multirow[t]{2}{*}{ EM } & \multicolumn{2}{|l|}{$\mathrm{HHS}$} \\
\hline & & Coef & $95 \% \mathrm{Cl}$ & & Coef & $95 \% \mathrm{Cl}$ \\
\hline
\end{tabular}

Cognitive dysfunction

\begin{tabular}{lllllll} 
Yes & 77 & - & - & 67 & - & - \\
No & 81 & 4 & $-4-11$ & 69 & 2 & $-4-8$ \\
Surgical treatment & & & & & & \\
$\quad$ Hip arthroplasty & 78 & - & - & 70 & - & - \\
$\quad$ Internal fixation & 79 & -0.5 & $-9-8$ & 66 & -4 & $-2-11$ \\
Age & - & -0.1 & $-0.7-04$ & - & -0.5 & $-0.9-0.1$ \\
Sex & & & & & & \\
$\quad$ Female & 82 & - & - & 69 & - & - \\
$\quad$ Male & 75 & -7 & $-14-1$ & 66 & -3 & $-9-3$ \\
ASA & & & & & & \\
$1-2$ & 80 & - & - & 70 & - & - \\
$3-4$ & 77 & -3 & $-4-10$ & 66 & -4 & $-2-10$ \\
\hline
\end{tabular}

Reoperation rates ranging from 8 to $19 \%$ have been reported for undisplaced or minimally displaced FNF treated with IF [3]. In the present study, we found a reoperation rate of $14 \%$, which is in concordance with previous studies [2]. The cumulative incidence of reoperation after IF for undisplaced or minimally displaced FNF was double that of arthroplasty for displaced FNF. There are a number of studies that have sought to predict the failure of undisplaced or minimally displaced FNF treated with IF. Posterior and ventral tilt on the lateral radiograph has been found to be a predictor of failure $[19,20]$. Other risk factors include advanced age, nutritional status, and capital impaction [21, 22].

The patient-reported outcomes after treatment with IF for undisplaced FNF have only been sparsely reported [2]. Rogmark et al. found that $40 \%$ of patients reported pain when walking and 25\% had pain at rest [5]. Despite uneventful healing of the undisplaced fracture, shortening of the femoral neck has been proposed as affecting postoperative hip function [23]. Elderly patients with reduced bone stock may be more susceptible for femoral neck shortening, mechanical failure, non-union, and avascular necrosis when treated with IF.

A recently published randomized controlled trial comparing hemiarthroplasty with IF for undisplaced FNFs found similar hip function measured by the Harris Hip Score [6]. However, regarding secondary outcomes, hemiarthroplasty led to improved mobility and fewer major reoperations.

Several factors affect the 1-year mortality such as age, cognitive impairment, pre-fracture mobility, and habitat.
In the present study, we found an overall 1-year mortality rate of $28 \%$ with no significant differences between the two groups at 1 and 2 years. Hip arthroplasty might provide most elderly patients with a definitive treatment, equipped with a low risk for reoperation that allows immediate unrestricted mobilization without increasing mortality.

Our results could be used as a pilot study and guidance in the set-up of a randomized controlled trial comparing hip arthroplasty and IF in the treatment of undisplaced or minimally displaced FNF [7]. Conducting register-based randomized controlled trials, which include a randomization module in a large, clinical register with unselected consecutive enrolment, can combine important features of a prospective randomized trial with the inclusiveness and efficiency of a large-scale clinical register [24-26]. A recently published meta-analysis on the treatment of undisplaced and minimally displaced FNF, based on a total of 579 randomized patients, concluded that hip arthroplasty might reduce the need for revision surgery [27].

This study has limitations including the non-randomized observational design. First, our sample is powered to test the study hypothesis but is not large enough to detect smaller differences between the two groups. Second, the used outcome measure HHS have some disadvantages such as ceiling and floor effects, which could mask the small difference in patients who scored their status as very high or very low. Finally, the choice of treatment modality was chosen by the treating surgeon, and this might have contributed some bias to the validity of the treatment method in some patients. These limitations are counterbalanced by the strengths of the study, which is a prospectively followed cohort with minimal drop-out and adequate follow-up period. By using the unique Swedish personal ID number, we collected data by a combination of a search of our inhospital surgical and medical database and follow-up visits which ensured a high data accuracy.

\section{Conclusion}

In this feasibility study, we found no differences in patient-reported outcomes between the studied groups, although IF required a higher rate of reoperations and had postoperative residual hip pain. Further randomized trials are needed to establish the optimal treatment of undisplaced FNF in the elderly.

\section{Acknowledgements}

We thank the research nurses Lotta Söderlind, Helene Sörell, and Elieann Broman for their outstanding work during the study.

\section{Authors' contributions}

All authors have participated in the (a) conception and design or analysis and interpretation of the data, (b) drafting the article or revising it critically for important intellectual content, and (c) approval of the final version. 


\section{Funding}

The authors received no financial support for the research, authorship, and/ or publication of this article.

\section{Availability of data and materials}

The datasets used and/or analyzed during the current study are available from the corresponding author on reasonable request.

\section{Ethics approval and consent to participate}

The study was conducted in accordance with the ethical principles of the Helsinki Declaration and was approved by the Ethics Committee of Umea University.

\section{Consent for publication}

Not applicable

\section{Competing interests}

The authors declare that they have no competing interests.

\section{Author details}

${ }^{1}$ Department of Surgical and Perioperative Sciences, Umeå University, Umeå, Sweden. ${ }^{2}$ Department of clinical sciences at Danderyds Hospital, Karolinska Institutet, Stockholm, Sweden. ${ }^{3}$ Department of Biomedical and Clinical Sciences (BKV), Linköping University, Linköping, Sweden. ${ }^{4}$ Institute of Clinical Sciences, The Sahlgrenska Academy, University of Gothenburg, Gothenburg, Sweden.

Received: 4 December 2019 Accepted: 6 July 2020

\section{Published online: 11 July 2020}

\section{References}

1. Rosengren BE, Björk J, Cooper C, Abrahamsen B. Recent hip fracture trends in Sweden and Denmark with age-period-cohort effects. Osteoporos Int 2017;28(1):139-49. https://doi.org/10.1007/s00198-016-3768-3.

2. Onativia IJ, Slullitel PA, Dilernia FD, Viezcas JMG, Vietto V, Ramkumar PN, et al. Outcomes of nondisplaced intracapsular femoral neck fractures with internal screw fixation in elderly patients: a systematic review. Hip Int. 2018; 28(1):18-28. https://doi.org/10.5301/hipint.5000532.

3. Gjertsen JE, Fevang JM, Matre K, Vinje T, Engesæter LB. Clinical outcome after undisplaced femoral neck fractures. Acta Orthop. 2011;82(3):268-74. https://doi.org/10.3109/17453674.2011.588857.

4. Rogmark C, Flensburg L, Fredin H. Undisplaced femoral neck fractures--no problems? A consecutive study of 224 patients treated with internal fixation. Injury. 2009;40(3):274-6. https://doi.org/10.1016/j.injury.2008.05.023 Epub 2008 Dec 13

5. Parker MJ, White A, Boyle A. Fixation versus hemiarthroplasty for undisplaced intracapsular hip fractures. Injury. 2008;39(7):791-5. https://doi.org/10.1016/j.injury.2008.01.011 Epub 2008 Apr 14

6. Dolatowski FC, Frihagen F, Bartels S, Opland V, Benth JS, Talsnes O, et al. Screw fixation versus hemiarthroplasty for nondisplaced femoral neck fractures in elderly patients: a multicenter randomized controlled trial. J Bone Joint Surg Am. 2019:101(2):136-44. https://doi.org/10.2106/JBJS.18.00316.

7. Fixation using Alternative Implants for the Treatment of Hip fractures (FAIT $H$ ) Investigators. Fracture fixation in the operative management of hip fractures (FAITH): an international, multicentre, randomised controlled trial. Lancet. 2017:389(10078):1519-27.

8. HEALTH Investigators, Bhandari M, Einhorn TA, Guyatt G, Schemitsch EH, Zura RD, et al. Total hip arthroplasty or hemiarthroplasty for hip fracture. N Engl J Med. 2019:381(23):2199-208.

9. Bernstein J, Weintraub S, Morris T, Ahn J. Randomized controlled trials for geriatric hip fracture are rare and underpowered: a systematic review and a call for greater collaboration. J Bone Joint Surg Am. 2019;101(24):e132.

10. Wolf O, Sjöholm P, Hailer NP, Möller M, Mukka S. Study protocol: HipSTHeR a register-based randomised controlled trial - hip screws or (total) hip replacement for undisplaced femoral neck fractures in elderly patients. BMC Geriatr. 2020:20(1):19. https://doi.org/10.1186/s12877-020-1418-2.

11. Mahomed N. N, Arndt D. C, McGrory B. J, Harris W.H. The Harris hip score: comparison of patient self-report with surgeon assessment. J Arthroplast 2001;16(5):575-580

12. Frihagen F, Grotle M, Madsen JE, Wyller TB, Mowinckel P, Nordsletten L. Outcome after femoral neck fractures: a comparison of Harris hip score, Eq- 5d and Barthel index. Injury. 2008;39(10):1147-56. https://doi.org/10.1016/j. injury.2008.03.027 Epub 2008 Jul 25.

13. Burgers PT, Van Geene AR, Van den Bekerom MP, Van Lieshout EM, Blom B, Aleem IS, et al. Reliability, validity, and responsiveness of the Western Ontario and McMaster universities osteoarthritis index for elderly patients with a femoral neck fracture. Int Orthop. 2012;36(8):1549-60. https://doi.org/ 10.1007/s00264-012-1569-7 Epub 2012 May 24.

14. Downie WW, Leatham PA, Rhind VM, Wright V, Branco JA, Anderson JA. Studies with pain rating scales. Ann Rheum Dis. 1978;37(4):378-81.

15. Rogmark C, Fenstad AM, Leonardsson O, Engesæter LB, Kärrholm J, Furnes $\mathrm{O}$, et al. Posterior approach and uncemented stems increases the risk of reoperation after hemiarthroplasties in elderly hip fracture patients. Acta Orthop. 2014;85(1):18-25. https://doi.org/10.3109/17453674.2014.885356 Epub 2014 Jan 24.

16. Mohammed J, Mukka S, Hedbeck CJ, Chammout G, Gordon M, Sköldenberg O. Reduced periprosthetic fracture rate when changing from a tapered polished stem to an anatomical stem for cemented hip arthroplasty: an observational prospective cohort study with a follow-up of 2 years. Acta Orthop. 2019;90(5):427-32. https://doi.org/10.1080/17453674.2019.1624339 Epub 2019 Jun 3.

17. Mukka S, Mellner C, Knutsson B, Sayed-Noor A, Sköldenberg O. Substantially higher prevalence of postoperative peri-prosthetic fractures in octogenarians with hip fractures operated with a cemented, polished tapered stem rather than an anatomic stem. Acta Orthop. Jun;87(3):257-61.

18. Sprowson AP, Jensen C, Chambers S, Parsons NR, Aradhyula NM, Carluke I, et al. The use of high-dose dual-impregnated antibiotic-laden cement with hemiarthroplasty for the treatment of a fracture of the hip: the fractured hip infection trial. Bone Joint J. 2016;98-B(11):1534-41.

19. Dolatowski FC, Adampour M, Frihagen F, Stavem K, Erik Utvåg S, Hoelsbrekken SE. Preoperative posterior tilt of at least $20^{\circ}$ increased the risk of fixation failure in garden-I and -|l femoral neck fractures. Bone Joint J. 2016;98-B(11):1534-41.

20. Sjöholm P, Otten V, Wolf O, Gordon M, Karsten G, Sköldenberg O, et al. Posterior and anterior tilt increases the risk of failure after internal fixation of garden I and II femoral neck fracture. Acta Orthop. 2019:4:1-8. https://doi. org/10.1080/17453674.2019.1637469 [Epub ahead of print]

21. Conn KS, Parker MJ. Undisplaced intracapsular hip fractures: results of internal fixation in 375 patients. Clin Orthop Relat Res. 2004;421:249-54.

22. Shimizu T, Miyamoto K, Masuda K, Miyata Y, Hori H, Shimizu K, et al. The clinical significance of impaction at the femoral neck fracture site in the elderly. Arch Orthop Trauma Surg. 2007:127(7):515-21 Epub 2007 Jun 1.

23. Zlowodzki M, Brink O, Switzer J, Wingerter S, Woodall J Jr, Petrisor BA, et al. The effect of shortening and varus collapse of the femoral neck on function after fixation of intracapsular fracture of the hip: a multi-Centre cohort study. J Bone Joint Surg Br. 2008;90(11):1487-94. https://doi.org/10.1302/ 0301-620X.90B11.20582.

24. Rothwell PM. External validity of randomised controlled trials: "to whom do the results of this trial apply?". Lancet. 2005 Jan 1-7;365(9453):82-93.

25. Mukka S, Sjöholm P, Chammout G, Kelly-Pettersson P, Sayed-Noor A, Sköldenberg O. External validity of the HOPE-Trial - hemiarthroplasty compared to total hip arthroplasty for displaced femoral neck fractures in octogenarians. JB JS Open Access. 2019 Jun 7;4(2):e0061. doi: https://doi. org/10.2106/JBJS.OA.18.00061. eCollection 2019 Apr-Jun.

26. Wachtell K, Lagerqvist B, Olivecrona GK, James SK, Fröbert O. Novel trial designs: lessons learned from thrombus aspiration during ST-segment elevation myocardial infarction in Scandinavia (TASTE) trial. Curr Cardiol Rep. 2016;18(1):11. https://doi.org/10.1007/s11886-015-0677-6.

27. Richards JT, Overmann AL, O' Hara NN, D' Alleyrand JC, Slobogean GP. Internal fixation versus arthroplasty for the treatment of nondisplaced femoral neck fractures in the elderly: a systematic review and meta-analysis. J Orthop Trauma. 2020:34(1):42-8.

\section{Publisher's Note}

Springer Nature remains neutral with regard to jurisdictional claims in published maps and institutional affiliations. 